\title{
Analysis of Injury Pattern \& Forensic Medicine Management in a Case of Bomb Blast Injury
}

\author{
Toshal Wankhade ${ }^{1}$, Deepak Bhagwat ${ }^{2}$, Ambedkar Ranjan ${ }^{3}$, B.H. Tirpude ${ }^{4}$, P.N. Murkey ${ }^{4}$, I.L. Khandekar ${ }^{4}$ \\ ${ }^{1}$ Senior Resident Dept of Forensic Medicine, AIIMS, Nagpur, ${ }^{2}$ Assistant Professor, Dept of Forensic Medicine, \\ Govt. Medical College, Gondia, ${ }^{3}$ Senior Resident, Dept of Forensic Medicine, Banaras Hindu University, \\ ${ }^{4}$ Professor, Dept of Forensic Medicine, MGIMS, Sevagram.
}

\begin{abstract}
Background: In 2016 midnight of summer a bomb blast occurred at ammunition depot Pulgaon. Blast was so severe that villagers in the radius of $10 \mathrm{~km}$ witnessed the blast wave. It had killed 19 people which included Army officers, soldier \& fire brigade men. As per police inquest \& alleged history given by eyewitness, an authority of Central Ammunition Depot at Pulgaon noticed fire at ammunition store of the depot. For this reason emergency task force team of the depot got activated and few army personnel including fire brigade personnel rushed to the spot to control the fire. But unfortunately large amount of ammunition blasted suddenly as the fire spread inside the ammunition storage. Because of this 19 parsons were died on the spot \& many were injured. To tackle the disaster civil authority were informed. When it was noted that total 19 personnel were died in the mishap, the District civil authority approached to Mahatma Gandhi Institute of Medical Sciences, Sevagram to send forensic medicine expert team to do spot Post Mortem (PM) examination. The main challenge before the forensic team was to establish the identity of the unidentified body apart from doing PM examination, so that the body can be handed over the kin as early as possible to end the uncertainty of their loved ones.
\end{abstract}

Aims \& Objective: Forensic casework was carried out with aim to study the pattern of injuries in the bomb blast cases, and to assess forensic management done in mass disaster.

Material and Method: Study was carried out on 15 dead bodies involved in the bomb blast injury. It includes observation based on post mortem examination and assessment of forensic management done by our team.

Result: Bomb blast injury includes complex of injuries like burn injury(100\%), decapitation (33\%), injury of internal abdominal organs $(40 \%) \&$ chest organs $(80 \%)$, fracture of bones (46\%), Amputation of limbs (33\%), and external mechanical injuries like contusion, abrasions and lacerations (100\%). Due to destructive injuries identity of the victim gets obscured (40\%).

Conclusion: Medicolegal postmortem, sample preservation and humanitarian action of establishing the identity of victims are the forensic management in bomb blast injury.

Keywords: Bomb blast, Mass disaster, Forensic Humanitarian action.

\section{Introduction}

\section{Corresponding Author:}

Dr. Deepak Bhagwat

Assistant Professor, Dept of Forensic Medicine, Govt.

Medical College, Gondia

e-mail: deepakbhagwat1890@gmail.com
Bomb blast is a kind of mass disaster. The WHO has defined disaster as an occurrence that causes damage, ecological disruption, loss of human life and deterioration of health and health services on a scale sufficient to warrant an extraordinary response from outside the affected community. A "Mass Disaster" 
is considered to have occurred when the number of casualties occurring in a single event exceeds twelve ${ }^{1}$. Management of disaster is multifaceted. It includes involvement of various agencies like law enforcement, safety \& Health care services. Forensic medicine role in the mass disaster includes

1) To retrieve and reconstruct bodies and fragmented bodies decently. 2) To establish personal identity. 3) To conduct autopsies on some or all of these bodies. 4) To establish the cause of death in same or all.

Apart from the routine forensic work forensic experts also has Humanitarian character in their task. This is known 'humanitarian forensic action'2. Mass disaster is not uncommon in India Hence preparedness should be there for such action. ${ }^{3}$. Present study involves handling of Bomb blast case by forensic expert.

Aims \& Objectives: Forensic casework was carried out with aim to study the pattern of injuries in the bomb blast cases, and to assess forensic management done in mass disaster.

\section{Material and Method}

Mass casualty due to bomb blast occurred at Army Ammunition depot in summer 2016. Present study was cross-sectional in design and included deceased succumbed to blast injuries. Total 19 causalities were reported. Post mortem examination was conducted on 15 bodies out of total 19 bodies. 4 bodies were referred to another agency for administrative purpose, and are excluded from present study.Each team consists of one forensic expert, one junior resident \& one mortuary attendant. Total 4 teams were formulated by MGIMS, Sevagram. Police officials collected the bodies and body parts which were submitted for postmortem examination. Bodies were categorised in two parts i.e.1) Deceased of which facial structured was intact and identity could be established and 2) Deceased wherein identity from facial features was not established due to its complete destruction.

Injuries were noted by proper examination of the dead body and samples are preserved in order to establish identity of unidentified bodies. Cause \& manner of the death of each person was determined based on observed trauma. Pattern of the injury is analyzed by comparing the existing injuries with the data from available literature. Standard Disaster Victim Identification (DVI) protocol ${ }^{4}$ was employed like visual identification, identification by interviews of next of kin and peer group and DNA analysis. Data was compiled and analysed with regards to trauma pattern and identification techniques involved.

Observation: Significant trauma was observed in almost all of the dead bodies with multiple body regions were involved. All the body areas had external mechanical injuries like abrasion, lacerations, contusions of various sizes and severity. Various major injuries observed amongst the bodies were as under.

Burn Injury: All 15 bodies have burn injuries these varied in extent and depth. Burn varies from superficial burn to complete charring of the body. (Fig.1). Inmost of the cases the blast had ripped off the clothing. Out of 15 bodies only 2 bodies was having minimal burn (up to $10 \%$ ) \& rest all of the cases were having severe burn injury starting from more than $50 \%$ to complete charring.

Head \& Neck Injuries: 13 out of $15(86 \%)$ of the victims had head $\&$ neck injury. Out of these 13 cases 5 cases had decapitation. (Fig $2 \& 3$ ).In remaining 8 cases, skull bone was fractured. The fracture skull varied from small fractures involving the base of the skull to major fractures of the vault. Decapitation injury ranged from level of lower jaw to transaction at the level of nipple in chest (1 case Fig.3). Brain injury involves laceration, oozing of brain matter \& intracranial hemorrhages which included extradural, subdural and subarachnoid hemorrhages.

Upper Trunk Injury (Thoracic Injury): Injuries on the upper trunk involve external injuries such as pressure abrasion, abrasions, contusions, laceration in almost all the cases. Most of the bodies were having both external as well as internal trauma of chest. In 12 out of 15 cases (80\%)internal chesttrauma was present which included various injuries like hemothorax, hemorrhages, contusions \& lacerations of lungs. Hemocardium, contusions \& lacerations of heart was also appreciated. In 3 out of total 15 (20\%) cases chest cavity was opened and charring of internal organs took place.

Lower Trunk (Abdominal Injury): Injuries on the lower trunk varied from external injuries such as pressure abrasion, abrasions, contusions, laceration in almost all the cases. 6 out of 15 cases $(40 \%)$ show intrabdominal trauma which include hemorrhages in abdominal cavity, contusions \& lacerations of abdominal organs. In 3 cases (20\%) abdominal cavity was opened and viscera were charred. 
Limb injury: Almost all the bodies had various kinds of injuries on limb varied from external mechanical injury such as abrasion, laceration, and contusions, fracture of bones or amputation of the limbs. Fracture of limbs was seen in 7 out of $15(47 \%)$ bodies out of these 5 (33\% of total) bodies had amputation of the limb.

Identification data: As all the deceased were serving personnel of the Ammunition Depot, list of missing personnel was provided by Depot Authority as they were deployed as a fire fighting team. 9 out of total $15(60 \%)$ persons were identified by facial features and body was handed over to relative after post mortem examination. Body was first identified by Depot authority and later on by relatives of the deceased. In 6 bodies (40\%) identity from facial structures could not be made out as body had decapitation injury as described earlier or their facial features unable to makeout due to extensive trauma. Among these 6 bodies, identity card of the deceased was found in two bodies (fig. 4). Still to confirm the identity of these bodies,sample was taken for DNA Analysis. Sample taken were blood on cotton cloth, the cloth was air dried and sealed in paper envelope. Sternal bones along with ribs were taken from all the 6 bodies for DNA analysis. On same day blood sample from parents of the missing persons was taken for matching the DNA profile with unidentified bodies. All samples are immediately forwarded to Regional Forensic Science Laboratory, Nagpur (RFSL). DNA analysis report was received within 48 hours and bodies handed over to relative by the police authority

To establish the identity following stepwise measures were taken.

1. Duty roaster from the ammunition depot authority was taken.

2. Number of the missing personnel was identified by taking the roll call by the depot authority.

3. Relatives of the all missing personnel informed regarding the incident and they all were called at the site for identification of the bodies.

3. Depot officer and relatives of the deceased identified 9 bodies whose facial structure was intact.

4. Among unidentified body few bodies had their identity card in their uniform which was preserved; blood is taken for blood grouping.

5. To confirm the identity by DNA fingerprinting sternal bone \& rib bones were preserved; blood was taken on cotton cloth. All these sample air dried and handed over to police as per norms.

6. Regional forensic lab, Nagpur was contacted by police authority and they were agreed to do DNA analysis within 2 days. Blood samples from the relatives were taken for the matching.

7. After the result of DNA analysis identity of all the deceased is established and bodies were handed over to police for further handover to relatives.

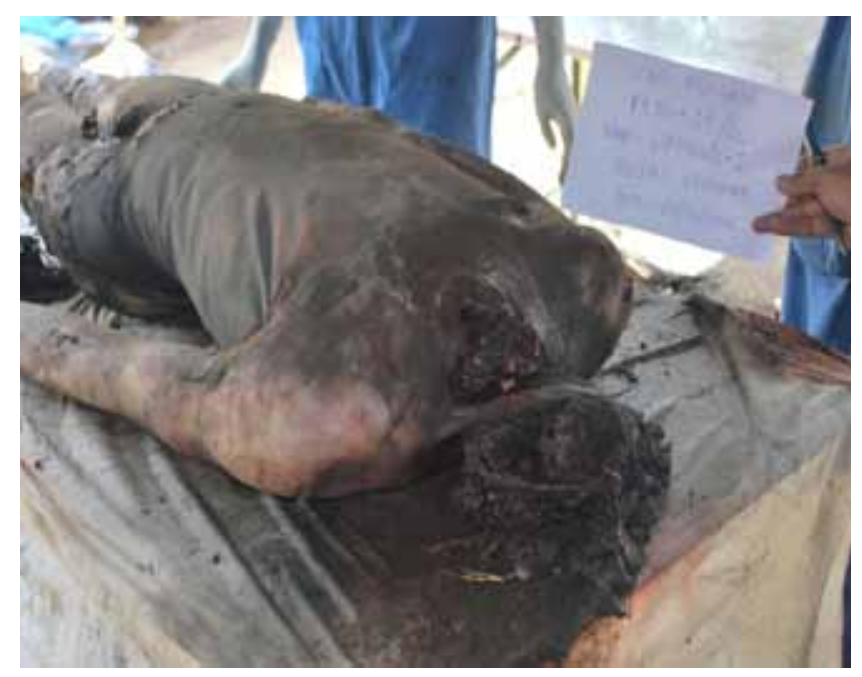

Fig. 1 Charring of body

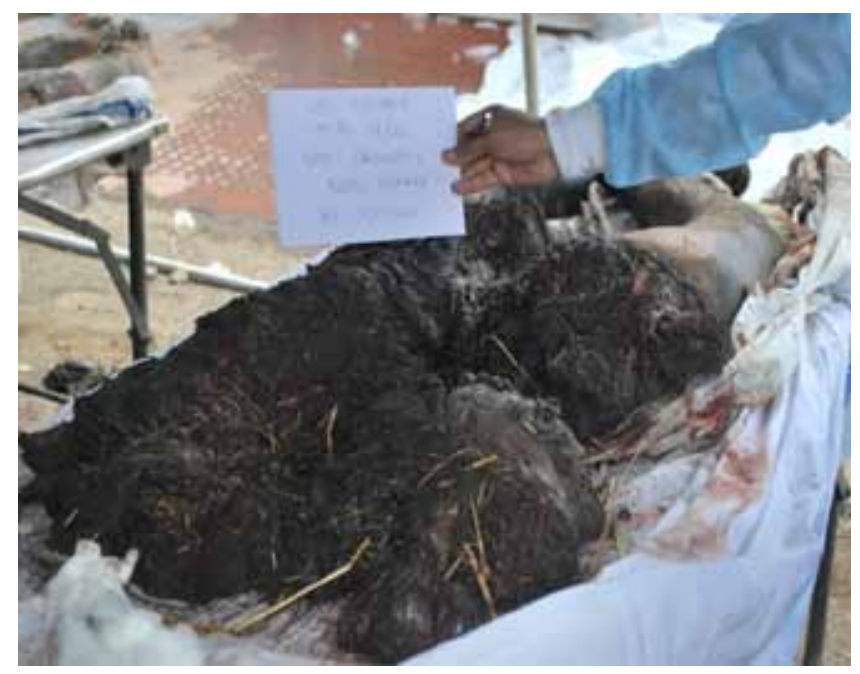

Fig. 2 Decapitation 


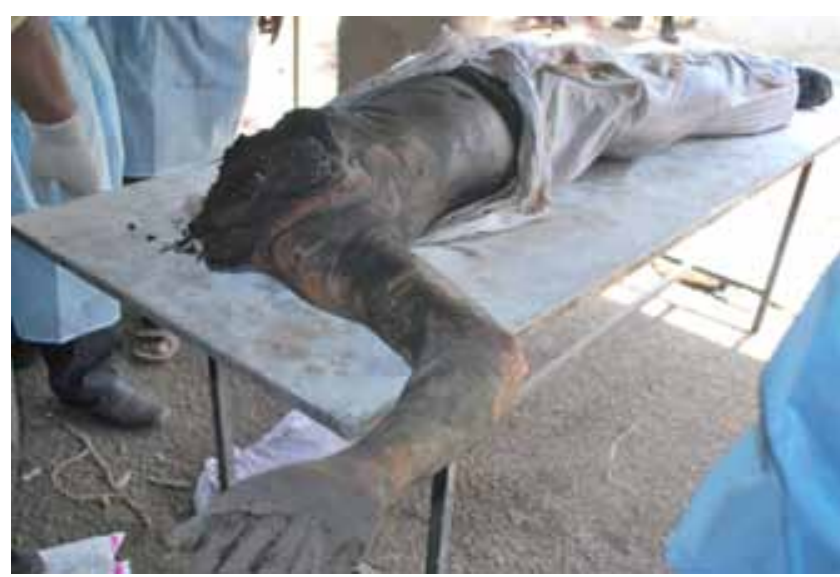

Fig. 3 Decapitation at Level chest

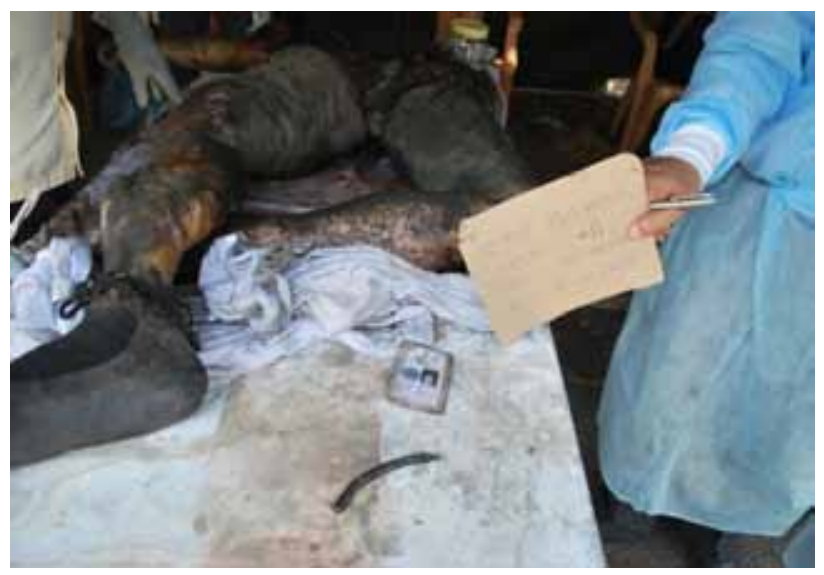

Fig. 4 Identity card \& Shrapnel

\section{Discussion}

Burn Injuries are commonly observed in blast injury. As per study by Water worthTA 19 out of $21(90 \%)$ victims was having burn injury. In present study all 15 cases (100\%) were having burnt injury. In study T A water worth most of the burn injury was superficial type but some injury were more extensive and charring of the tissue occurred due to flash. In present study also the burn pattern varies from superficial to deep and charring observed. However number of cases involved more in our study aslarge amount of ammunition store blasted at single time.

In the study by KahanaT ${ }^{6} 73$ of 171 (43\%)of cadaver is identified by visual method and in remaining cases scientific method are used for the identification before burial of the body. In our study, 9 cases out 15 (60\%) had identified with facial characters. However to identify the unknown cases DNA analysis was performed. Differences in finding between these two studies may be due to less number of cases involved in current study and list of missing persons was known. However, the study done by water worth ${ }^{5}$ shows similarity with findings in our study pertaining to number of unidentified persons.

In present study 13 out of $15(86 \%)$ cases suffered head, neck $\&$ face injury. This varied from skull fracture to complete decapitation of the head. Our findings matches with the study by $\mathrm{T}$ A Waterworth ${ }^{5}$ where 15 out 21 cases $(70 \%)$ cases have the head injury in varying severity. However our findings differs with the study by Yogender Malik $^{7}$ where $33 \%$ cases involved with injury at head region. This variation may be due to the variation in severity and amount of ammunition blast in these studies.

As per study of waterworth ${ }^{5}$ out of 21 bodies (43\%) person suffered limb amputation. These findings are similar to our study where amputation of limb is seen in 5 cases $(33 \%)$. Extremities injuries are one of the commonest involvements in bomb blast incident. In study bysue Mallonee ${ }^{8} .75 \%$ of the victims suffered with the limb injury. In our study all the (100\%) victims were having various kinds of injuries on limbs ranging from abrasion, laceration, fracture to amputation of limbs. Fracture of the bone is noted in 7 out of 15 cases. (46\%)

All the bodies were having external injuries over upper \& lower trunk. In our study $12(80 \%)$ individuals were having internal chest trauma that includes contusions \& laceration of the lungs and hemorrhages in chest cavity \& $3(20 \%)$ person were having open chest wound. $6(40 \%)$ cases were having contusion and laceration of various abdominal organs out of which $3(20 \%)$ bodies were having open abdominal wound. Similar finding was seen in study by waterworth ${ }^{5}$.

\section{Conclusion}

Team work is must in mass disaster. It includes proper coordination between investigating agency, administration authority \& medical team. In current case District authority advised for formation of medical team, the team examined the bodies and collected the proper samples, police agency done their inquest formalities quickly and liaised with RFSL for quick analysis of sample and due to this team work situation was handled on fast track.

Inclusion of forensic expert is must in this kind of situation. Due to involvement expert proper sample collection, their preservation, performing the autopsy and establishing the identity of unknown victim was done with great proficiency. 
DNA typing allows the identification of individual, as long as sufficient DNA can be recovered from the sample(s). This is true even when the conditions are such that the victims' remains are fragmented.

Regarding injury pattern complex nature of the injuries is present in case of bomb blast. Establishing the identity remains the main challenge due to severity of injury.

The common conception of forensic medicine is that they are involved with gathering evidence against crime. That is, they are focused on assignment of criminal responsibility. However, there has always been a humanitarian character to forensic medicine. 'Managing the dead, including protecting their dignity but also helping to identify them to prevent and resolve the tragedy of people missing' is the humanitarian forensic action is evident in present study.

\section{Conflict of Interest: Nil}

\section{Source of Funding: Nil}

Acknowledgement: Thanks to Dr Mandar Sane, Assistant Professor Forensic Medicine, AIIMS, Nagpur for providing Valuable reference to formulate this article.

Ethical Clearance: Taken from Institutional Ethical committee as per Institute Norms

\section{References}

1. Reddy KSN. The Essentials of Forensic Medicine and Toxicology, $34^{\text {th }}$ Edition, The Health Science Publisher, New Delhi, India2017; 269-270.

2. Cordner S, Tidball-Binzc M. Humanitarian forensic action - Its origins and future. Forensic Sci Int. 2017;279:65-71.

3. Gupta BD. Mass disasters: A preparedness plan book with particular emphasis on mortuary services. J Indian Acad Forensic Med., 2004; 26(2).

4. Interpol, Disaster Victim Identification [Web Page], 2009 Available at: http://www.interpol. int/Public/DisasterVictim/Default.asp, (accessed 07.05.2016).

5. Waterworth TA, Carr MJT. An analysis of the post-mortem findings in the 21 victims of the Birmingham pub bombings. Injury. 7:89-95.

6. Hiss J, Kahana T. Trauma and identification of victims of suicidal terrorism in Israel. Mil Med. 2000;165(11):889-93.

7. Malik Y, Chaliha RR. Serial bomb blasts in NorthEast India: A postmortem study. J Indian Acad Forensic Med. 2012;34(1):52-4.

8. Sue Mallonee R, Shariat S, Stennies G, Waxweiler R, Hogan D, Jordan F. Physical injuries and fatalities resulting from the Oklahoma City bombing. JAMA. 1996;276(5):382-7. 